\title{
A stepwise integrated risk-assessment framework in aquaculture: the case of sea lice tolerance to freshwater treatments on salmon farms
}

\author{
Emilie Laurin ${ }^{1}$, Marit Stormoen ${ }^{2}$, Crawford Revie ${ }^{1,3}$, Javier Sanchez ${ }^{1, *}$ \\ ${ }^{1}$ Department of Health Management, Atlantic Veterinary College, University of Prince Edward Island, Charlottetown, \\ Prince Edward Island, C1A 4P3 Canada \\ ${ }^{2}$ Norwegian University of Life Science, Faculty of Veterinary Medicine, Oslo, Norway \\ ${ }^{3}$ Department of Computer and Information Sciences, University of Strathclyde, Glasgow, UK
}

\begin{abstract}
Aquaculture studies are often faced with data limitations when carrying out a quantitative risk assessment. Consolidating results from a literature search of potentially applicable methods, we propose a stepwise integrated methods approach that incorporates foundations from an antimicrobial resistance framework, the Office International Epizooties risk model, quantitative microbial risk assessment and infectious disease transmission models. We suggest that an initial ranking profile can be used to prioritize more in-depth qualitative and quantitative risk assessments, when data are available. The ranking method was done using a software that provides practical and interactive graphics for visualizing the impact of different factors and their respective weights on the likelihood of undesirable events (hazards) occurring. For this step, we illustrate how to include available data to obtain ranking results for decision makers using information from a recent sea lice freshwater tolerance literature review (Groner et al. 2019) that identified a gap in quantitative data. In our case example, for copepodid sea lice life stages, hypothetically changing how much experts believe that location and time are important factors revealed the most impact on the ranking for different degrees of freshwater tolerance evolution (no evolution, various partial options, known evolution). The factors 'location' and 'time', as well as 'freshwater treatment', have the greatest impact on the ranking for the preadult sea lice life-stages model. Results from our proposed ranking method can help to drive decisions around interpreting the various factors as they apply to mitigation planning and prioritizing those that should be included in further research. Additionally, we identify where quantitative data could be incorporated, as they become available, into a full risk assessment model with suggested models for a freshwater tolerance risk analysis framework.
\end{abstract}

KEY WORDS: Risk analysis $\cdot$ Risk ranking $\cdot$ Framework $\cdot$ Sea lice $\cdot$ Freshwater tolerance

\section{INTRODUCTION}

Risk analyses (RAs) look at the likelihood (see Table 1 for a definition of RA terminology used) that undesirable events (hazards) will occur, together with the consequences of their occurrence (Greiner et al. 2004, Peeler et al. 2007). When faced with

${ }^{*}$ Corresponding author: jsanchez@upei.ca uncertainty about the likelihood of occurrence of a hazard (the phenomena causing the potential risk) and the associated consequences (therefore, risk $=$ likelihood $\times$ consequences), decision makers can use RAs for evidence-based, transparent decisions and guidance documents (Vose 2001) in order to reduce the incidence of the hazard (Smith 2001, Peeler et al. 
2007). RAs are founded on both qualitative and quantitative methods. Semi-quantitative methods have also been proposed to provide score results when too few quantitative data are available, as is often the case for aquatic-focused RAs (Vose 2001, Peeler et al. 2007, Beaudequin et al. 2015). Once the hazard has been identified, the goal of an RA is to evaluate the risk of introducing the hazard, followed by identifying pathways through which the probability of exposure to the hazard can occur, as well as other factors that can contribute to and affect the estimation of the risk and any uncertainty related to that estimate (Travis \& Hueston 2001, Peeler et al. 2007). When risks are considered harmful, the impact of mitigation measures are also incorporated into the RA.
The lack of information necessary to understand the impact of new management practices on current and future estimates of risk is one of the major challenges when assessing those practices in production systems, such as aquaculture, particularly where immediate harm-reduction can have negative effects later. For example, in salmon aquaculture, control of sea louse parasites is a major challenge, costing approximately $9 \%$ of farm revenues and resulting in as much as a $16 \%$ reduction in salmon biomass (Abolofia et al. 2017). Use of chemotherapeutants to control sea louse infestations on salmon farms has led to the evolution of resistance to some medicinal treatments over a relatively short time frame (1 to 2 decades; reviewed

Table 1. Definition of risk analyses terminology used

\begin{tabular}{|c|c|}
\hline Terminology & Definition \\
\hline Consequence & Outcome of hazard occurring \\
\hline Factor(s) & Information that can positively or negatively impact the risk \\
\hline $\begin{array}{l}\text { Full or complete risk analyses } \\
\text { framework }\end{array}$ & $\begin{array}{l}\text { Complete process to assess risk estimate(s), by identifying hazards, probability of } \\
\text { exposure to the hazard and subsequent consequences. It can use more than one model } \\
\text { and should identify uncertainty around the probability and risk estimate(s). It should also } \\
\text { include risk mitigation and risk communication steps. In our proposed method, it also } \\
\text { includes a risk ranking step }\end{array}$ \\
\hline Hazard & Undesirable event, phenomenon causing the potential risk \\
\hline Likelihood & Introduction and exposure assessment \\
\hline $\begin{array}{l}\text { Measurement score, } \\
\text { measurement scale, } \\
\text { measurement }\end{array}$ & $\begin{array}{l}\text { How a factor or subfactor will be measured in order to estimate the score or directional } \\
\text { result of each one. Can be presented as a category (e.g. yes/no/maybe) or linear (e.g. } \\
\text { number of days) }\end{array}$ \\
\hline $\begin{array}{l}\text { Multicriteria decision analysis } \\
\text { (MCDA) }\end{array}$ & $\begin{array}{l}\text { A risk modelling framework for handling complex decisions, where a decision is based } \\
\text { on more than one factor }\end{array}$ \\
\hline Multimodal & More than one model \\
\hline Outcome & The hazard defined in degrees or levels or alternatives \\
\hline Phi & $\begin{array}{l}\text { How preference is estimated. Positive flow (phi+) indicates the level to which a particular } \\
\text { outcome is dominating all others, negative flow (phi-) indicates the level to which a given } \\
\text { outcome is being dominated, and net flow (net phi) is used to provide an approximate } \\
\text { measure of the overall preference of an outcome }\end{array}$ \\
\hline $\begin{array}{l}\text { Preference, preference level, } \\
\text { preference value }\end{array}$ & $\begin{array}{l}\text { The quantitative or score value that identifies which outcome is preferred over another, } \\
\text { i.e. it is more influential on the risk estimate or score }\end{array}$ \\
\hline Risk & Likelihood $\times$ consequence \\
\hline Risk estimate & A quantitative estimate for the calculated risk \\
\hline Risk profile & $\begin{array}{l}\text { A schematic or outline of all the applicable factors, subfactors and weights for a unique } \\
\text { scenario used in the ranking method to define a risk score }\end{array}$ \\
\hline $\begin{array}{l}\text { Risk ranking, } \\
\text { ranking }\end{array}$ & $\begin{array}{l}\text { A model that ranks or prioritizes (by preference values) different degree(s) of a hazard } \\
\text { occurring }\end{array}$ \\
\hline Risk scores & $\begin{array}{l}\text { Quantitative or semi-quantitative estimates of risk (the preference values in the ranking } \\
\text { method) as defined by a set of specific factors, subfactors and weights }\end{array}$ \\
\hline Subfactor(s) & Further divisions of factors to define differences between conditions of a factor \\
\hline Uncertainty & Lack of precise knowledge of input values \\
\hline Weight & $\begin{array}{l}\text { The degree of influence of a factor or subfactor(s). Combined weights refer to combining } \\
\text { the weight of a factor and its subfactors into one weight estimate }\end{array}$ \\
\hline
\end{tabular}


in Aaen et al. 2015). The lack of effective medicinal treatments, stricter regulations and industry efforts to reduce medicine use for sea lice has precipitated the development of non-medicinal methods for sea louse control such as mechanical, freshwater and thermal treatments (Overton et al. 2018). RA could aid in strategizing how and when these nonmedicinal methods should be used to improve practices and avoid the evolution of treatment tolerance.

A literature review by Groner et al. (2019) summarized current knowledge about the potential evolution of freshwater and low-salinity tolerance in sea lice and other copepodids that infect wild and/or farmed salmonids. However, major quantitative data gaps were identified that preclude more complete RAs. To address risk-based decisions in aquaculture when such major quantitative data limitations exist, we propose a step-wise approach that uses more than one model (multimodal) for an integrated risk analysis framework. Multicriteria decision analysis (MCDA) offers a framework for handling complex decisions that need to account for conflicting objectives. When quantitative data are not available, risk-ranking methods can be carried out prior to a more complete RA (CAC 2011). MCDA can enable the ranking of factors that can positively or negatively impact the risk of hazard(s) occurring (Fazil et al. 2008, Oidtmann et al. 2011, Martínez et al. 2015). Risk ranking prioritizes current qualitative data or semi-qualitative factors (see the example of antimicrobial resistance models for knowledge data gaps as presented in CAC 2011) to drive decisions around interpreting these various factors as they apply to mitigation planning and prioritizing those that can guide research to obtain the data required for a more complete quantitative RA (Peeler et al. 2007). We illustrate this ranking method using the case example of the evolution of freshwater tolerance in sea lice. Following the ranking, we suggest a possible integrated RA method that would include various models that focus on both qualitative and quantitative data for the case example.

\section{MATERIALS AND METHODS}

We have created a step-by-step workflow for assessing the risk of sea lice developing tolerance to freshwater treatments (Fig. 1), following the regulatory World Organization for Animal Health (Office International Epizooties; OIE 2019) RA model (which does not include a ranking method) as well as the antimicrobial RA model from the Executive Committee of the Codex Alimentarius Commission (CAC 2011), which does include a ranking method. Our approach focuses on how a ranking method can first be developed for aquaculture studies with data limitations, and then applying that ranking method for our case study using the criteria identified by Groner et al. (2019). For our case study, we present hypothetical scenarios where different factors may have more or less influence (weight) on the hazard occurring and how changing the weight can change the rank-

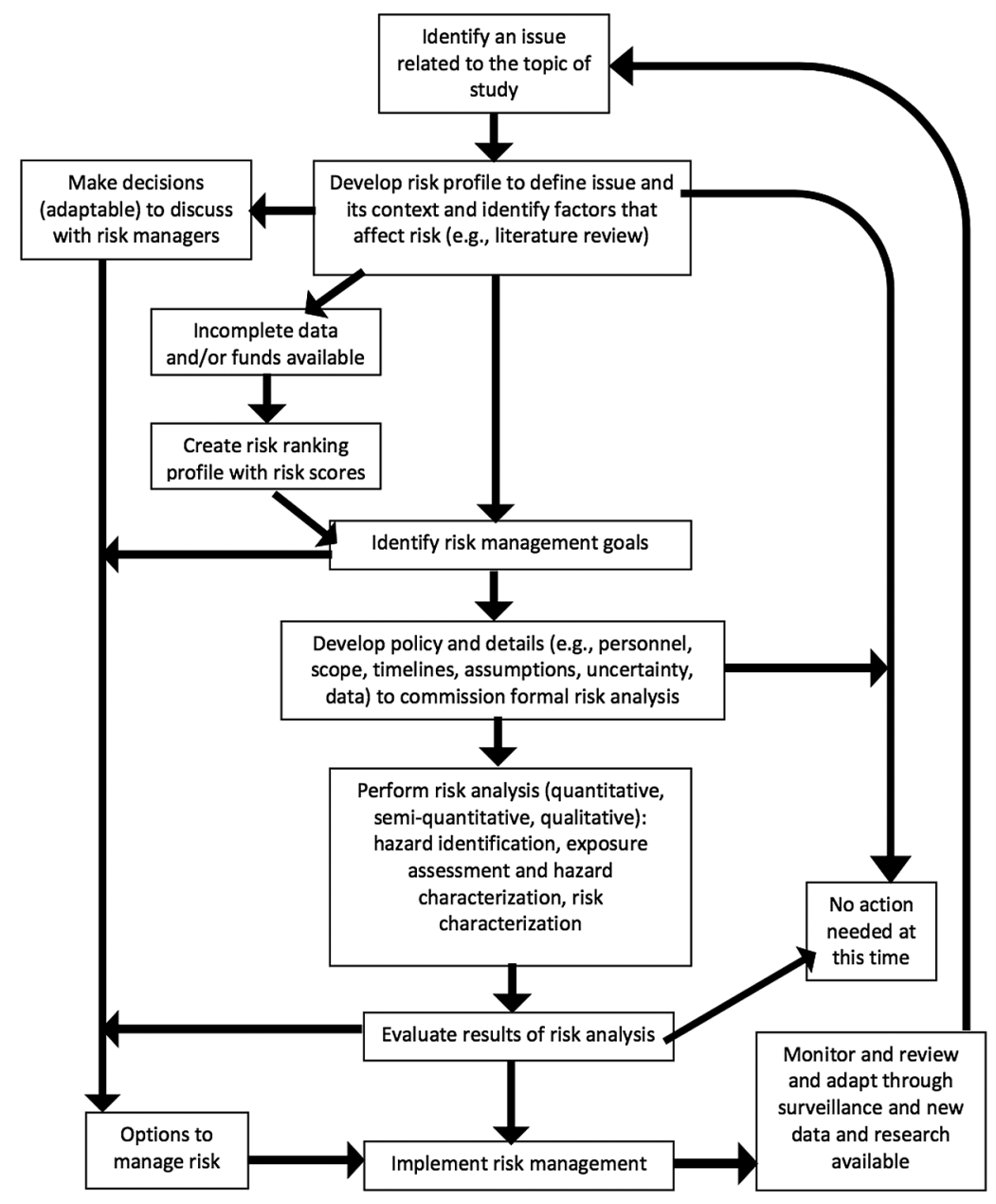

Fig. 1. Proposed workflow (based on CAC 2011) for assessment of the risk of sea lice evolving freshwater tolerance 
ing. We include methods and examples with the case study about how to incorporate available data and visualize results of the ranking through the use of a user-friendly, graphical risk-ranking tool (Visual Promethee 1.4 software VP Solutions, 2013; www. promethee-gaia.net). Because we did not have adequate quantitative data available to illustrate, with the case example, a complete RA model beyond the ranking, we present instead several different model types from the literature that could be included and adapted when quantitative data become available and to help prioritize research for the case example.

\subsection{Developing the ranking method}

We used MCDA to enable ranking of factors that can positively or negatively impact the risk of the hazard occurring. These factors are identified from evidence-based information and can be quantitative or semi-quantitative. A factor can be further divided into various levels of subfactors to define differences between conditions that define the factor. This method could be used as part of the framework outlined in Fig. 1 to create a risk profile (a schematic or outline of all the applicable factors, subfactors and weights).

Once factors and subfactors are established and justified, we need to define how each will be measured (e.g. linear scale, categories, etc.). These measurements should reflect evidence-based information from the risk profile and expert opinion (CAC 2011). Finally, each factor is assigned weights to reflect its impact or influence on ranking. Therefore, a combination of different weights for each factor and subfactor(s) will be used to create a risk score. The higher the score, the higher the preference of one being ranked higher than another.

We chose the PROMETHEE II method (Belton \& Stewart 2002, Figueira et al. 2005, Fazil et al. 2008) as the best example to generate the ranking method and assess the preferences in the light of different weights or influence of factors over others. Belton \& Stewart (2002) and Figueira et al. (2005) provide a detailed explanation of the mathematics and the analysis behind the preference calculations. Briefly, the degree of preference, $\Pi(a, b)$, for outcome option $a$ against outcome option $b$, is calculated according to the formula:

$$
\Pi(a, b)=\sum_{j=1}^{k} w_{j} P_{j}(a, b)
$$

where $w$ is the weight of factor $j$, and $P_{j}(a, b)$, which measures the preference for option $a$ over option $b$, comes from the preference function. Ranking is generated in PROMETHEE using what the methodology calls 'positive flows', 'negative flows' and 'net flows'. The positive flow (phi+) indicates the level to which a particular outcome (in risk ranking this would be a degree of the hazard occurring) is dominating all others, the negative flow (phi-) indicates the level to which a given outcome is being dominated, and the net flow (net phi) is used to provide an approximate measure of the overall preference of an outcome. Each outcome is based on a unique pre-defined set of factors and subfactors, as well as assigned weights that are used for the preference function.

\section{RESULTS}

\subsection{Hypothetical examples of using the ranking method for the case study}

In our case example, we define the hazard as freshwater tolerance evolution in sea lice, and we define the risk score from the ranking method here as the preference value of our outcomes (risk of evolving freshwater tolerance) occurring as defined by a combination of factors, subfactors and weights. For our case example, we created 2 models, using the Visual PROMETHEE software, based on 2 Lepeophtheirus salmonis sea lice life stages, namely copepodids and preadults. We did not merge them into one model for the sake of simplicity for our illustration of the method, due to numerous interactions and combinations that occur between life stage and various criteria (in particular, length of exposure time to freshwater; see the Supplement at www.int-res.com/ articles/suppl/q012p417_supp.pdf).

Our different outcomes (degrees of freshwater tolerance occurring, described in detail in the following paragraph) provide various possibilities that are ranked (preference for one or more over another) based on the risk scores. For our example, we incorporate factors identified in the Groner et al. (2019) review: genetics, metapopulation dynamics, and selection-strength factors such as environment and freshwater treatments (Fig. 2). These 4 broad factors were further subdivided into subfactors. In Table 2, we list our selected factors and their associated subfactors, including how we defined them, the scale we used for measuring changes in them, and the weight of importance we assigned them in our example models. We selected the measurement scales and 
weights based on information obtained from Groner et al. (2019), Ljungfeldt et al. (2017) and expert opinion (M. Andrews, Norwegian University of Life Sciences [NMBU]). Assigned weights in Table 2 are author-selected and are used to demonstrate how to incorporate overall (combined) versus individual factor and subfactor weight components. Combined weights refer to combining the weight of a factor and its subfactors into one weight estimate. We used some of the freshwater exposure time by life stage interactions described in the supplement as well as information from Groner et al. (2019), Ljungfeldt et al. (2017) and expert opinion (M. Andrews) for defining the scales, scores and weights for each of the respective sea lice life-stage models (Table 3 ).

We created 3 degrees of sea lice evolving tolerance to freshwater treatments (Table 3): 'no' (sea lice death, therefore no tolerance), 'partial' (possible occurrence) and 'known' (no change in sea lice survival and behavior, therefore tolerance). We created several 'partial' options for freshwater tolerance evolution, whereby the outcome is

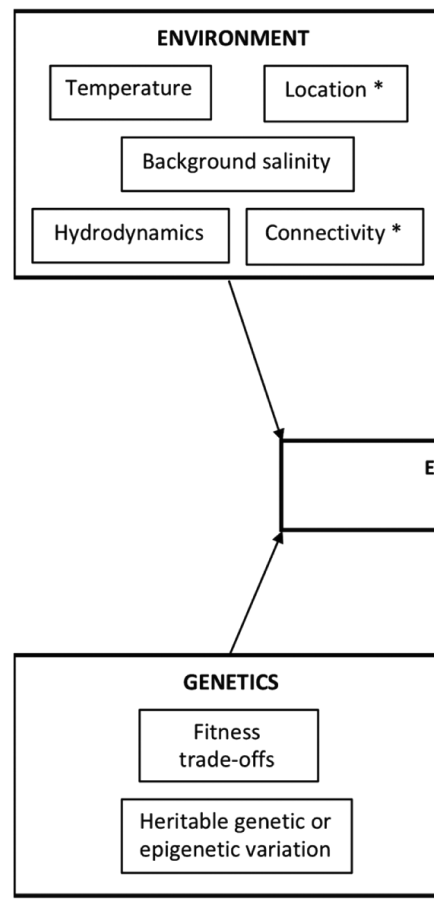

Fig. 2. Key factors identified from the recent literature review (Groner et al. 2019) that may affect the risk of sea lice evolving tolerance to freshwater treatments. Asterisks indicate factors with further explanatory notes as follows: location (environmental salinity, exposure to freshwater run-off, sensitivity of associated lice population to freshwater, etc.); connectivity (farm to farm, wild to farm, farm to wild, direction of water current, density of wild versus farmed hosts, etc.); duration (length of exposure, number of repeated exposures); and permanent freshwater cap (snorkel cages, skirts) vival or $>50 \%$ survival or unknown \% survival) or inhibited development. These 'partial' degrees of freshwater tolerance were based on information from various field and experimental studies of sea lice responses to various salinity thresholds (see the supplement and Table 3) (Ljungfeldt et al. 2017, Crosbie et al. 2019, Sievers et al. 2019, expert opinion [M. Andrews]). In our case example, the degrees of freshwater tolerance with the highest net phi corresponds to a higher risk score of freshwater tolerance evolution occurring in sea lice, considering all the specific information used to define that model.

Because the influence of criteria and sub-criteria can be weighted as described previously, the VP walking weights (proportion of weight assigned to each factor and subfactor[s]) allow for an interactive visualization of how the ranking of the degrees of freshwater tolerance can be influenced if the weights are changed. In our case example, for copepodid life stages, hypothetically changing the weights for the 'location' and 'time' subfactors (from those weights we assigned them as described in Table 2) had the most impact on the ranking (positive or negative direction of net phi value) of the different degrees of freshwater tolerance (no, various partial options, known). The subfactors 'location' and 'time', as well as 'intervention', had the greatest impact on the ranking for the preadult life-stages model. In Fig. 3, we visually present 2 different options of various changes in combined weights assigned to our factors of interest and the resulting effect on the ranking's preference values for each life-stage model. The first combined-weight option (Fig. 3A, column 1) is the one presented in Table 2, while in the second weight option (Fig. 3A, column 2), salinity, time, and location are assigned higher combined weights. Differences in ranking (net phi value) for the degrees of freshwater tolerance are visualized depending on the sea lice life stage (Fig. 3B,C). Variations were greater for the 'partial' freshwater tolerance options. The level of net phi flow (higher preference and ranking) for 'known' freshwater tolerance also slightly varies depending on the different weights assigned in each model. With all of these examples, we show that the analyses available through the VP software can be an effective and interactive means for visualizing the 
Table 2. Selected factor and subfactors (based on Ljungfeldt et al. 2017, Groner et al. 2019, Sievers et al. 2019, and expert opinion [M. Andrews]), for use in our Visual PROMETHEE example to evaluate risk ranking effect of these factors for sea lice evolving tolerance to freshwater (FW). Assigned weights are author-selected and are used to demonstrate how to incorporate overall (combined) versus individual factor and subfactor weight components. Combined weights refer to combining the weight of a factor and its subfactors into one weight estimate. The direction of the measurement value (either increase or decrease in number value or percent value) corresponds to an increased risk of sea lice evolving tolerance to freshwater

\begin{tabular}{|c|c|c|c|c|c|c|}
\hline $\begin{array}{l}\text { Factor } \\
\text { (weight) }\end{array}$ & $\begin{array}{l}\text { Subfactor } \\
\text { (weight) }\end{array}$ & $\begin{array}{l}\text { Combined } \\
\text { weight }(\%)\end{array}$ & $\begin{array}{c}\text { Factor } \\
\text { definition }\end{array}$ & $\begin{array}{l}\text { Measurement } \\
\text { type }\end{array}$ & $\begin{array}{l}\text { Measurement } \\
\text { definition }\end{array}$ & Direction \\
\hline \multirow[t]{2}{*}{$\begin{array}{l}\text { Genetics } \\
(50 \%)\end{array}$} & $\begin{array}{l}\text { Heritability } \\
\quad(80 \%)\end{array}$ & 40 & $\begin{array}{l}\text { Presence of heritable } \\
\text { genetic or epigenetic } \\
\text { variation for FW } \\
\text { tolerance }\end{array}$ & Qualitative & $\begin{array}{c}1 \text { (none), } 2 \text { (present), } \\
3 \text { (unknown) }\end{array}$ & Increase \\
\hline & $\begin{array}{c}\text { Fitness } \\
\text { trade-offs }(20 \%)\end{array}$ & 10 & $\begin{array}{l}\text { Decreases in sea lice } \\
\text { fitness that are associated } \\
\text { with FW tolerance }\end{array}$ & Qualitative & $\begin{array}{c}1 \text { (none), } 2 \text { (present), } \\
3 \text { (unknown) }\end{array}$ & Increase \\
\hline \multirow[t]{3}{*}{$\begin{array}{l}\text { Exposure } \\
(20 \%)\end{array}$} & Salinity (33\%) & 7 & $\begin{array}{l}\text { Parts per thousand of } \\
\text { saline concentration } \\
\text { measured in water }\end{array}$ & Categorical & $\begin{array}{c}\text { Range } \\
\text { (0 to } 30 \% \text { salinity) }\end{array}$ & Decrease \\
\hline & Intervention $(33 \%)$ & 7 & $\begin{array}{l}\text { Type of freshwater } \\
\text { treatment used }\end{array}$ & Qualitative & $\begin{array}{c}1 \text { (none), } \\
2 \text { (>1 treatment type), } \\
3 \text { (wellboat), } \\
4 \text { (unknown) }\end{array}$ & Increase \\
\hline & Time $(33 \%)$ & 7 & $\begin{array}{l}\text { Duration of exposure } \\
\text { to hyposaline water }\end{array}$ & Categorical & Range (0 to $7 \mathrm{~h}$ ) & Increase \\
\hline \multirow[t]{2}{*}{$\begin{array}{l}\text { Population/ } \\
\text { environment } \\
(30 \%)\end{array}$} & Lice/hosts $(50 \%)$ & 15 & $\begin{array}{l}\text { Type of hosts (farm or wild) } \\
\text { and connectivity between } \\
\text { populations }\end{array}$ & Qualitative & $\begin{array}{l}1 \text { (no connectivity), } \\
2 \text { (wild > farmed), } \\
3 \text { (farmed > wild), } \\
4 \text { (farmed > wild; } \\
\text { more connectivity), } \\
5 \text { (unknown) }\end{array}$ & Increase \\
\hline & Location (50\%) & 15 & $\begin{array}{l}\text { Sensitivity } \\
\text { (or decreased tolerance) } \\
\text { of a population to freshwater } \\
\text { treatment that is due to } \\
\text { various environmental or } \\
\text { other non-heritable factors }\end{array}$ & Qualitative & $\begin{array}{c}1 \text { (more sensitivity), } \\
2 \text { (less sensitivity), } \\
3 \text { (unknown sensitivity) }\end{array}$ & Increase \\
\hline
\end{tabular}

risk scores and weights of various degrees of freshwater tolerance occurring, while allowing the user to readily make changes to factors, subfactors and weights, as these information change or become available. Results from this visual ranking method can help to drive decisions around interpreting various factors and subfactors in mitigation planning and prioritizing which ones to include in further RA and research (see Fig. 1).

\subsection{Proposed integrated RA framework}

We also propose an integrated RA framework (Fig. 4). This could be developed pending available data and resources, to support the particular goals of an RA team. It is also dependent on the outcomes and applicability of the risk ranking related to those goals (see steps in Fig. 1 and the ranking examples discussed previously). The framework integrates the traditional OIE hazard identification, release, exposure and consequence assessments with portions of 2 specific RA modelling foundations, namely quantitative microbial risk assessment (QMRA) and infectious disease transmission (IDT) models for a more inclusive and applicable framework to the diversity of data in aquaculture studies. In Table 4, we present examples from the literature for different modelling approaches that can be incorporated and/or modified, including ranking and the MCDA models. Brouwer et al. (2018) define QMRA models as focusing on factors in the environment that characterize pathogen dynamics and subsequent exposure. These models are based on dose-response models and are used mainly in regulatory settings, as in the case of the OIE model. In contrast, IDT models focus more on 
Table 3. Subfactor values for each of our suggested outcomes (degrees of freshwater tolerance evolution). We used 2 example life-stage models in Visual PROMETHEE (C: copepodid; P: preadult). n/a: not applicable. Hosts: type of hosts (farm or wild) and connectivity between populations; location: sensitivity (or decreased tolerance) of a population to freshwater treatment that is due to various environmental or other non-heritable factors

\begin{tabular}{|c|c|c|c|c|c|c|c|c|}
\hline $\begin{array}{l}\text { Outcome } \\
\text { (freshwater } \\
\text { tolerance) }\end{array}$ & $\begin{array}{c}\text { Life } \\
\text { stage }\end{array}$ & Heritability & $\begin{array}{l}\text { Fitness } \\
\text { trade-offs }\end{array}$ & $\begin{array}{c}\text { Salinity } \\
\text { (psu or ppt) }\end{array}$ & $\begin{array}{c}\text { Subfactor } \\
\text { Intervention }\end{array}$ & $\begin{array}{c}\text { Time } \\
\text { (h) }\end{array}$ & Hosts & Location \\
\hline \multirow[t]{2}{*}{ No } & $\mathrm{C}$ & No & No & 30 & None & 0.0 & None & More \\
\hline & $\mathrm{P}$ & No & No & 30 & None & 0.0 & None & More \\
\hline \multirow[t]{2}{*}{ Known } & $\mathrm{C}$ & Yes & Yes & 0 & Wellboat & 7.0 & \multirow{2}{*}{$\begin{array}{l}\text { Farm }>\text { wild }_{i} \\
\text { more connectivity } \\
\text { farmed }>\text { wild; } \\
\text { more connectivity }\end{array}$} & \multirow{2}{*}{$\begin{array}{l}\text { Less } \\
\text { Less }\end{array}$} \\
\hline & $\mathrm{P}$ & Yes & Yes & 0 & Wellboat & 7.0 & & \\
\hline Partial > 50\% & $\mathrm{C}$ & Yes & Yes & 13 & Unknown & 1.0 & Farm $>$ wild & Less \\
\hline lice survival 1 & $\mathrm{P}$ & Yes & Yes & 5 & Unknown & 1.0 & Farm $>$ wild & More \\
\hline Partial > 50\% & $\mathrm{C}$ & Yes & Yes & 23 & Unknown & 1.0 & Farm > wild & More \\
\hline lice survival 2 & $\mathrm{P}$ & $\mathrm{n} / \mathrm{a}$ & $\mathrm{n} / \mathrm{a}$ & $\mathrm{n} / \mathrm{a}$ & $\mathrm{n} / \mathrm{a}$ & $\mathrm{n} / \mathrm{a}$ & $\mathrm{n} / \mathrm{a}$ & $\mathrm{n} / \mathrm{a}$ \\
\hline Partial <30\% & $\mathrm{C}$ & $\mathrm{n} / \mathrm{a}$ & $\mathrm{n} / \mathrm{a}$ & $\mathrm{n} / \mathrm{a}$ & $\mathrm{n} / \mathrm{a}$ & $\mathrm{n} / \mathrm{a}$ & $\mathrm{n} / \mathrm{a}$ & $\mathrm{n} / \mathrm{a}$ \\
\hline lice survival & $\mathrm{P}$ & Yes & Yes & 0 & Unknown & 1.0 & Unknown & Unknown \\
\hline Partial ?\% & $\mathrm{C}$ & Yes & Yes & 7 & $>1$ & 0.5 & Wild $>$ farm & Unknown \\
\hline lice survival & $\mathrm{P}$ & Yes & Yes & 5 & $>1$ & $\mathrm{n} / \mathrm{a}$ & Wild > farm & Unknown \\
\hline Partial inhibited & $\mathrm{C}$ & Yes & No & 25 & Unknown & 0.5 & Unknown & Unknown \\
\hline lice development & $\mathrm{P}$ & $\mathrm{n} / \mathrm{a}$ & $\mathrm{n} / \mathrm{a}$ & $\mathrm{n} / \mathrm{a}$ & $\mathrm{n} / \mathrm{a}$ & $\mathrm{n} / \mathrm{a}$ & $\mathrm{n} / \mathrm{a}$ & $\mathrm{n} / \mathrm{a}$ \\
\hline
\end{tabular}

population factors and how pathogens are spread between and among populations (Brouwer et al. 2018). These models are based on susceptible-infectiousrecovered (SIR) models to define the interacting population groups. Outputs from these models, in particular system dynamic IDT models (versus agentbased), can provide unit frequency (e.g. average population estimates) that are dependent on different conditions and can be used for determining the probability and likelihood of the hazard occurring (see examples in Greiner et al. 2013, Beaudequin et al. 2015, McEwan et al. 2016, Rico et al. 2017, Wright et al. 2018). Because it is set in a Bayesian framework to handle uncertainty, we suggest that the Aldrin et al. (2017) salmon lice (L. salmonis) model may be adapted for a quantitative RA, with factors such as temperature dependence (see also Myksvoll et al. 2018), population and individual fish demographics, transmission rates and control measures (see their papers for specific equations and descriptions of assumptions made within their models; e.g. a decreased effect of treatment over time due to tolerance development and maturation times). However, the Aldrin et al. (2017) model does not include salinity, as they had insufficient salinity data; yet as we are considering freshwater as a treatment modality, we propose adjusting their model to include freshwater treatment(s).

\section{DISCUSSION}

We proposed including in the RA framework a visual method to prioritize or rank degrees of freshwater tolerance for future research and mitigation planning, using the Visual PROMETHEE 1.4 software (VP Solutions, 2013) to analyze a risk profile classified within the MCDA framework. Our proposed RA framework was adapted from the import risk guidelines of the World Organization for Animal Health (OIE 2019; based on the model defined by Covello \& Merkhofer 1993), by incorporating a riskranking step before conducting the risk assessment. The 4 steps required for the OIE RA are: (1) hazard identification (in our case example, this would be the evolution of freshwater tolerance in sea lice); (2) risk assessment (including how a hazard is introduced, pathways by which animals can be exposed to the hazard or experience it, results or consequences of having the hazard or being exposed to it, and estimating the risk of exposure and possible results of exposure); (3) risk management; and (4) risk communication. These formal RAs can range from including qualitative to semi-quantitative to full quantitative parameter estimates for probability and likelihood outcomes.

It is important that transparency around assumptions and uncertainty be maintained, including inter- 
A

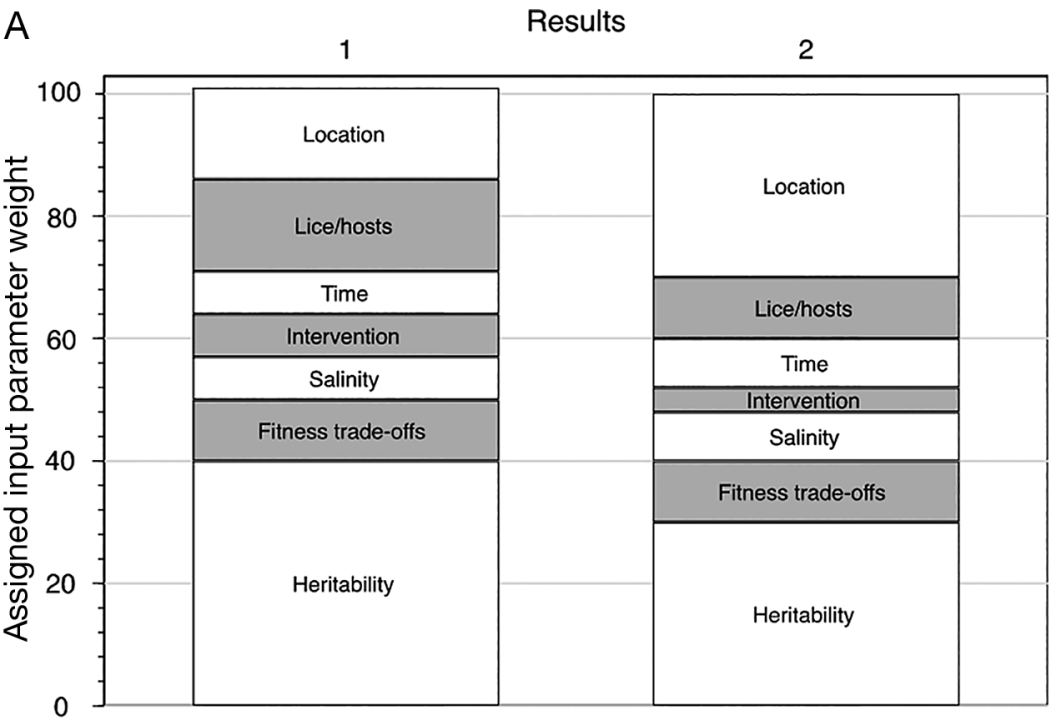

\section{B}
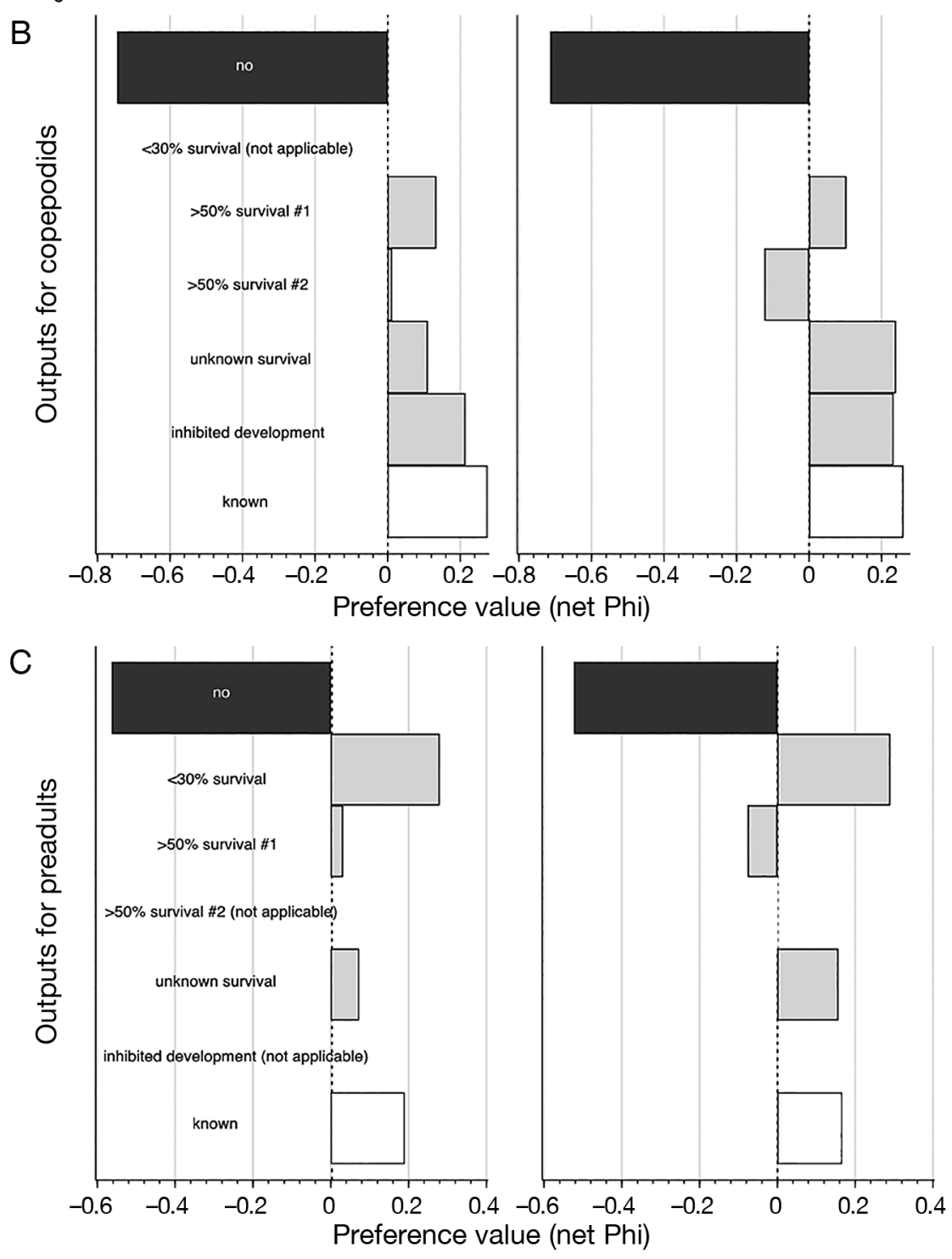

actions between factors that can affect the interpretation of risk estimates (CAC 2011). For example, interactions between farmed and wild fish as well as environmental factors can impact fish stress and increase RA model uncertainty in aquaculture studies (Travis \& Hueston 2001, Sievers et al. 2019). Kristoffersen et al. (2018) and Myksvoll et al. (2018) discussed how various environmental factors (e.g. temperature, location, presence of farmed fish, etc.) can change the behaviour of sea lice and/or fish, depending on whether the fish are wild or farmed. In addition, the length and number of treatments, salinity and the potential for reattachment of sea lice could all affect the preference of one degree of freshwater tolerance over another (Wright et al. 2018, Crosbie et al. 2019, Sievers et al. 2019). There is a greater risk of the hazard occurring as there is more uncertainty around an unknown presence or quantity of a factor or subfactor. Uncertainty due to interaction(s) between factors can be mitigated by applying different weighting schematics to key factors and subfactors. However, it can be difficult to obtain quantitative data for selecting weights. Expert opinion or literature review information can be used, in which case this should be reported (Fazil et al. 2008). Groner et al. (2019) identified several gaps in available knowledge for each of the selected factors for our

Fig. 3. Changes in net phi values (preference) by sea lice life stage: (B) copepod; (C) preadult, of different degrees of freshwater tolerance occurring, according to weights presented in (A). The 2 result options are based on 2 different combined-weighting schemes assigned to the following factors and subfactors. 1: genetics $=50 \%$ (with heritability $=80 \%$ and fitness trade-offs $=20 \%$ ), exposure $=20 \%$ (with salinity, intervention, and time each $33 \%$ ) and population/environment $=30 \%$ (with lice/hosts and location each $50 \%$ ); 2: genetics $=40 \%$ (with heritability $=75 \%$ and fitness trade-offs $=25 \%$ ), exposure $=20 \%$ (with salinity and time each $40 \%$ and intervention $=20 \%$ ) and population/environment $=40 \%$ (with lice/hosts $=$ $25 \%$ and location $=75 \%$ ) 


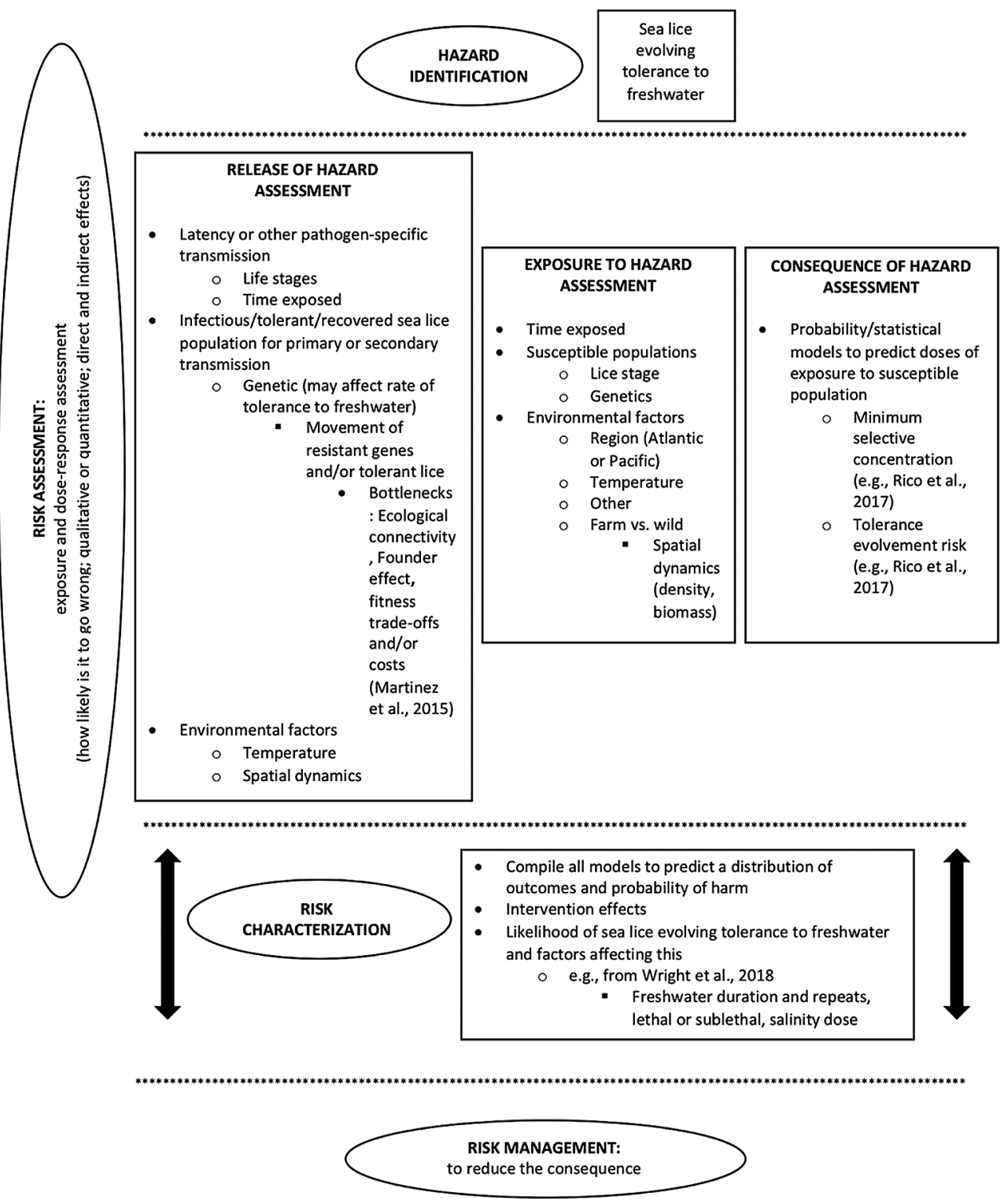

Fig. 4. Suggested risk analysis framework incorporating quantitative methods (Brouwer et al. 2018, Kristoffersen et al. 2018) and additional risk and quantitative examples for characterizing the risk of sea lice evolving tolerance to freshwater. Ovals represent the OIE risk model categories

case example that either increased uncertainty or led to non-accessibility of risk estimates.

The degrees of the hazard occurring that are used can be changed based on the set of factors, subfactors and weights used as new empirical information becomes available, or if the effect of various rankings (for example, midpoint versus extreme values) may need to be evaluated depending on the purposes of the RA (see Fig. 1). The practical interpretation of ranking results is dependent on the inclusion of factors and up-to-date information that will define different management or mitigation protocols. The ranking (net phi value) of some degrees of fresh- water tolerance that are more or less likely to occur over others will help decision makers to determine those that are to be preferred over others as a firstchoice management strategy in order to decrease the likelihood of sea lice evolving tolerance to freshwater treatments. For instance, for the hypothetical copepodid model, the 'known' degree of freshwater tolerance had the highest net phi value, while the 'partial' freshwater tolerance degrees were grouped lower, mostly in pairs evenly spaced, and specifically 'inhibited development' was second in preference to 'known'. Practically, if treatment and management protocols include the defined factors and subfactors 
Table 4. Various modelling approaches discussed that can be incorporated or modified for a full risk analysis framework, including risk ranking, for evaluation of the risk of freshwater tolerance evolution occurring in sea lice. QMRA: quantitative microbial risk assessment; SD: system dynamic; BN: Bayesian network; OIE: World Organization for Animal Health; MCDA: multi-criterion decision analysis

\begin{tabular}{|c|c|c|c|}
\hline Modelling approach & Species/uses & Main goal of models & Citation \\
\hline QMRA and SD & Waterborne bacteria & $\begin{array}{l}\text { Review to look at integration of QMRA } \\
\text { and SD for: risk of waterborne outbreaks (QMRA) } \\
\text { and quantification of transmission pathways (SD) }\end{array}$ & $\begin{array}{l}\text { Brouwer et al. } \\
\qquad(2018)\end{array}$ \\
\hline $\begin{array}{l}\text { SD } \\
\text { Linear model }\end{array}$ & $\begin{array}{l}\text { Gill disease in } \\
\text { Atlantic salmon }\end{array}$ & $\begin{array}{l}\text { Assess how freshwater exposure duration } \\
\text { altered the detachment and survival } \\
\text { of gill-isolated Neoparamoeba perurans }\end{array}$ & $\begin{array}{l}\text { Wright et al. } \\
\qquad(2018)\end{array}$ \\
\hline $\begin{array}{l}\text { Probabilistic model - } \\
\text { exposure concentrations } \\
\text { to antibiotics }\end{array}$ & $\begin{array}{l}\text { Antibiotic } \\
\text { concentrations } \\
\text { in pond water }\end{array}$ & $\begin{array}{l}\text { Risk of antibiotic resistance development } \\
\text { in environmental compartments } \\
\text { in aquaculture production systems }\end{array}$ & $\begin{array}{l}\text { Rico et al. } \\
\quad(2017)\end{array}$ \\
\hline QMRA and BN & $\begin{array}{l}\text { Foodborne and } \\
\text { waterborne pathogens }\end{array}$ & $\begin{array}{l}\text { Evaluation of the capabilities } \\
\text { and challenges of current } \\
\text { QMRA methods and BN models }\end{array}$ & $\begin{array}{l}\text { Beaudequin et al. } \\
\qquad(2015)\end{array}$ \\
\hline QMRA and BN & Food safety & $\begin{array}{l}\text { Explore Bayesian computational } \\
\text { statistics in the context of QMRA. } \\
\text { Explore the analogy between } \\
\text { Monte Carlo modelling and } \\
\text { Bayesian inference }\end{array}$ & $\begin{array}{l}\text { Greiner et al. } \\
\text { (2013) }\end{array}$ \\
\hline Hydrodynamic model & Salmon lice & $\begin{array}{l}\text { Hydrodynamic ocean model system, } \\
\text { particle tracking model (infestation pressure) } \\
\text { and Bayesian statistical model }\end{array}$ & $\begin{array}{l}\text { Myksvoll et al. } \\
\text { (2018) }\end{array}$ \\
\hline $\begin{array}{l}\text { Spatial-temporal linear } \\
\text { mixed model }\end{array}$ & Sea lice & $\begin{array}{l}\text { To assess relative spatial and temporal } \\
\text { risks associated with farm-origin salmon lice. }\end{array}$ & $\begin{array}{l}\text { Kristoffersen et al. } \\
\text { (2018) }\end{array}$ \\
\hline $\begin{array}{l}\text { Qualitative and quantitative, } \\
\text { including risk ranking and } \\
\text { OIE approaches }\end{array}$ & $\begin{array}{l}\text { Foodborne } \\
\text { antimicrobial } \\
\text { resistance }\end{array}$ & $\begin{array}{l}\text { Discuss the formal OIE risk analysis } \\
\text { approach, as well as qualitative steps, } \\
\text { quantitative steps and risk ranking } \\
\text { steps for evaluating the risk of foodborne } \\
\text { antimicrobial resistance in humans }\end{array}$ & CAC (2011) \\
\hline $\begin{array}{l}\text { MCDA } \\
\text { (PROMETHEE) }\end{array}$ & Food safety & $\begin{array}{l}\text { To demonstrate the use of ranking methods } \\
\text { in microbial food safety decision making to } \\
\text { reduce microbial risks }\end{array}$ & $\begin{array}{l}\text { Fazil et al. } \\
\quad(2008)\end{array}$ \\
\hline $\begin{array}{l}\text { MCDA - additive } \\
\text { risk score model }\end{array}$ & $\begin{array}{l}\text { Fish farm } \\
\text { microbiological risks }\end{array}$ & $\begin{array}{l}\text { To rank freshwater salmonid fish farms in a } \\
\text { country or region free of a specified pathogen } \\
\text { for the likelihood of disease introduction } \\
\text { and spread of the specified pathogen }\end{array}$ & $\begin{array}{l}\text { Oidtmann et al. } \\
\text { (2011) }\end{array}$ \\
\hline Decision chart & $\begin{array}{l}\text { Antibiotic resistance, } \\
\text { human pathogens }\end{array}$ & $\begin{array}{l}\text { Risks associated with genes that are present } \\
\text { in environmental resistomes (likelihood of their } \\
\text { introduction into human pathogens, and the } \\
\text { consequences for the treatment of infections) }\end{array}$ & $\begin{array}{l}\text { Martínez et al. } \\
\qquad(2015)\end{array}$ \\
\hline
\end{tabular}

and their weights, then the factors for the 'known' degree of freshwater tolerance are more likely to fail (i.e. copepodid sea lice are more likely to evolve freshwater tolerance), followed by those that cause inhibited development. On the other hand, if we look at the preadult model, '<30\% survival' had the highest ranking (i.e. the most likely to see freshwater tolerance evolution), followed closely by 'known', and then less likely (larger gap in net phi values) were the remaining 'partial' degrees of freshwater toler- ance (i.e. these are better choices if we want to avoid freshwater tolerance occurring).

In our case example, we were not able to consider the uncertainty of the output of closer-ranked degrees of freshwater tolerance for simplicity's sake, but as data become more available, then a subsequent quantitative model can help to handle the uncertainty. In general, quantitative RA probabilities and sensitivity analyses are identified mathematically through stochastic simulation models using 
software, such as @RISK, to perform Monte Carlo simulations (Greiner et al. 2004, Peeler et al. 2007). All model assumptions for each step need to be transparently described (Greiner et al. 2004). For transparency, RAs also need to describe all factors that contribute to uncertainty ('lack of precise knowledge of input values') around the risk estimate and assumptions made in lieu of available data (Travis \& Hueston 2001). For example, some of the factors from the Tasmanian study by Wright et al. (2018) could be used in a quantitative RA model (e.g. time limits, sublethal or lethal outcomes, salinity doses, etc.). For another example, Rico et al. (2017) looked at a probabilistic approach to the development of antimicrobial resistance in aquaculture and tolerance to antibiotic treatments; it may be possible to alter their calculations for exposure concentration, probability, minimum selective concentration (this would only be applicable if looking at ranges of salinity, not just freshwater) and tolerance development risk for tolerance to freshwater treatments instead of antibiotic treatments. One of the major differences, however, is that chemical resistance frequently evolves from a single-point mutation, whereas freshwater tolerance may be polygenic (reviewed in Groner et al. 2019). Rico et al. (2017) suggests that the tolerance development risk 'can be used to derive tolerance threshold concentrations', but they caution that the model needs to 'adequately define exposure standards protective of background tolerance levels...' (based on factors including amount of exposure, length of exposure time, dose, environmental factors, susceptibility factors in fish and fish biomass in environments). However, because of limitations and uncertainties, they suggest their approach should only be used for the initial phase of RA.

\section{CONCLUSION}

As an aid to focusing future research for aquaculture studies with quantitative data limitations, we propose including a risk ranking method in an integrated RA framework that can assist decision makers, dependent on their goals, as well as data and funding availabilities. We suggest that an initial ranking method can be used to prioritize more indepth qualitative and quantitative RAs, using a software that provides practical and interactive graphics for visualizing the impact of different factors and their respective weights on the risk of the hazard occurring. We have presented hypothetical examples around risk ranking for 2 different sea lice life stages, with currently available data from recent freshwater tolerance research and literature reviews. In addition, we present a flowchart that can assist future indepth and quantitative RAs, particularly for freshwater tolerance evolution in sea lice as additional data become available.

Acknowledgements. This project was funded in kind by the Canada Excellence Research Chair in Aquatic Epidemiology programme (Atlantic Veterinary College, Prince Edward Island), the University of Prince Edward Island, and the Norwegian Seafood Research Fund (FHF; Project Number 901438). We thank Melanie Andrews from the Norwegian University of Life Sciences for her expert opinion. We also thank Maya L. Groner for her expert opinion and guidance with the research development; her contribution was carried out while serving as a visiting scientist with the US Geological Survey (any use of trade, firm, or product names is for descriptive purposes only and does not imply endorsement by the US Government).

\section{LITERATURE CITED}

Aaen SM, Helgesen KO, Bakke MJ, Kaur K, Horsberg TE (2015) Drug resistance in sea lice: a threat to salmonid aquaculture. Trends Parasitol 31:72-81

Abolofia J, Asche F, Wilen JE (2017) The cost of lice: quantifying the impacts of parasitic sea lice on farmed salmon. Mar Resour Econ 32:329-349

Aldrin M, Huseby RB, Stien A, Grøntwedt RN, Viljugrein H, Jansen PA (2017) A stage-structured Bayesian hierarchical model for salmon lice populations at individual salmon farms - estimated from multiple farm data sets. Ecol Model 359:333-348

Beaudequin D, Harden F, Roiko A, Stratton H, Lemckert C, Mengersen K (2015) Beyond QMRA: modelling microbial health risk as a complex system using Bayesian networks. Environ Int 80:8-18

Belton V, Stewart T (2002) Multiple criteria decision analysis: an integrated approach. Kluwer Academic Publishers, Boston

Brouwer AF, Masters NB, Eisenberg JNS (2018) Quantitative microbial risk assessment and infectious disease transition modeling of waterborne enteric pathogens. Curr Environ Health Rep 5:293-304

CAC (Codex Alimentarius Commission) (2011) Guidelines for risk analysis of foodborne antimicrobial resistance (CAC/ GL 77-2011). CAC, Rome. www.codexalimentarius.net/ download/standards/11776/CXG_077e.pdf

Covello VT, Merkhofer MW (1993) Risk assessment methods: approaches for assessing health and environmental risks. Plenum Publishing, New York, NY

Crosbie T, Wright DW, Oppedal F, Johnsen IA, Samsing F, Dempster T (2019) Effects of step salinity gradients on salmon lice larvae behaviour and dispersal. Aquacult Environ Interact 11:181-190

FFazil A, Rajic A, Sanchez J, McEwen S (2008) Choices, choices: the application of multi-criteria decision analysis to a food safety decision-making problem. J Food Prot 71:2323-2333

Figueira J, Greco S, Ehrgott M (2005) Multiple criteria decision analysis: state-of-the-art surveys. Springer, New York, NY 
Greiner M, Paisley L, Hostrup-Pedersen J, Lo Fo Wong DMA and others (2004) Principles, application areas and an example of risk assessment conducted at the Danish Institute for Food and Veterinary Research. Berl Munch Tierarztl Wochenschr 117:177-181

Greiner M, Smid J, Havelaar AH, Müller-Graf C (2013) Graphical models and Bayesian domains in risk modelling: application in microbiological risk assessment. Prev Vet Med 110:4-11

Groner ML, Laurin E, Stormoen M, Sanchez J, Fast M, Revie CW (2019) Evaluating the potential for sea lice to evolve freshwater tolerance as a consequence of freshwater treatments in salmon aquaculture. Aquacult Environ Interact 11:507-519

Kristoffersen AB, Qviller L, Helgesen KO, Vollset KW, Viljugrein H, Jansen PA (2018) Quantitative risk assessment of salmon louse-induced mortality of seaward-migrating post-smolt Atlantic salmon. Epidemics 23:19-33

Ljungfeldt LER, Quintela M, Besnier F, Nilsen F, Glover KA (2017) A pedigree-based experiment reveals variation in salinity and thermal tolerance in the salmon louse, Lepeophtheirus salmonis. Evol Appl 10:1007-1019

Martínez JL, Coque TM, Baquero F (2015) What is a resistance gene? Ranking risk in resistomes. Nat Rev Microbiol 13:116-123

McEwan GF, Groner ML, Burnett DL, Fast MD, Revie CW (2016) Managing aquatic parasites for reduced drug resistance: lessons from the land. J R Soc Interface 13: 20160830

Myksvoll MS, Sandvik AD, Albretsen J, Aspin L and others (2018) Evaluation of a national operational salon lice monitoring system - from physics to fish. PLOS ONE 13: e0201338

Oidtmann BC, Crane CN, Thrush MA, Hill BJ, Peeler EJ (2011) Ranking freshwater fish farms for the risk of pathogen introduction and spread. Prev Vet Med 102:329-340

Editorial responsibility: Bengt Finstad,

Trondheim, Norway
OIE (2019) Import risk analysis. OIE Aquatic animal health code, Chapter 2.1. OIE, Paris

* Overton K, Dempster T, Oppedal F, Kristiansen TS, Gismervik K, Stien LH (2019) Salmon lice treatments and salmon mortality in Norwegian aquaculture: a review. Rev Aquacult 11:1398-1417

*Peeler EJ, Murray AG, Thebault A, Brun E, Giovaninni A, Thrush MA (2007) The application of risk analysis in aquatic animal health management. Prev Vet Med 81:3-20

Rico A, Jacobs R, Van den Brink PJ, Tello A (2017) A probabilistic approach to assess antibiotic tolerance development risks in environmental compartments and its application to an intensive aquaculture production scenario. Environ Pollut 231:918-928

Sievers M, Oppedal F, Ditria E, Wright DW (2019) The effectiveness of hyposaline treatments against host-attached salmon lice. Sci Rep 9:6976

Smith P (2001) Assessing the risks associated with the use of antimicrobial agents in aquaculture. In: Rodgers CJ (ed) Proceedings of risk analysis in aquatic animal health. World Organisation for Animal Health (OIE) conference in Paris, France, February 2000. OIE, Paris, p 175-184

Travis D, Hueston W (2001) Factors contributing to uncertainty in aquatic animal risk analysis. In: Rodgers CJ (ed) Proceedings of risk analysis in aquatic animal health. OIE conference in Paris, France. February 2000. OIE, Paris, p 27-35

Vose D (2001) Qualitative versus quantitative risk analysis and modelling. In: Rodgers CJ (ed) Proceedings of risk analysis in aquatic animal health. OIE conference in Paris, France, February 2000. OIE, Paris, p 19-26

Wright DW, Nowak B, Oppedal F, Crosbie P, Stien LH, Dempster T (2018) Repeated sublethal freshwater exposures reduce the amoebic gill disease parasite, Neoparamoeba perurans, on Atlantic salmon. J Fish Dis 41: $1403-1410$

Submitted: January 21, 2020; Accepted: August 17, 2020

Proofs received from author(s): October 13, 2020 